Национална конференция с международно участие „ГЕОНАУКИ 2020“

National Conference with international participation "GEOSCIENCES 2020"

https://doi.org/10.52215/rev.bgs.2020.81.3.25

\title{
Thermal decomposition of ktenasite
}

\section{Термична декомпозиция на ктенасит}

\author{
Zlatka Delcheva ${ }^{1}$, Nadia Petrova ${ }^{1}$, Tsveta Stanimirova ${ }^{2}$ \\ Златка Делчева ${ }^{1}$, Надя Петрова ${ }^{1}$ Цвета Станимирова ${ }^{2}$ \\ ${ }^{1}$ Institute of Mineralogy and Crystallography, Bulgarian Academy of Sciences, 107 Acad. G. Bonchev Str., 1113 Sofia, Bulgaria; \\ E-mail: zlatka.delcheva.1989@gmail.com \\ ${ }^{2}$ University of Sofia “St. Kliment Ohridski”, Faculty of Geology and Geography, Department of Mineralogy, Petrology \\ and Economic Geology, 15 Tzar Osvoboditel Blvd., 1000 Sofia, Bulgaria
}

Keywords: ktenasite, thermal decomposition, decomposition products.

\section{Introduction}

The ktenasite is a copper zinc hydroxy-sulfatehydrate mineral first found by Kokkoros (1950) in the Kamariza mine, Lavrion (Greece). This mineral occurs as an alteration products of copper-zinc ores and slags. The crystal structure of ktenasite was solved by Mellini and Merlino (1978) in space group $P 2_{I} / c$ and characterized by interrupted sheets ${ }_{\infty}^{2}\left[(\mathrm{Cu}, \mathrm{Zn})_{2}(\mathrm{OH})_{3} \mathrm{O}\right]^{-}$of distorted copper-zinc octahedra. Sulfate groups are connected to both sides of the octahedral sheet by corner sharing. The resultant composite tetrahedral-octahedral sheets own negative charge, which is compensating by interlayer $\left[\mathrm{Zn}\left(\mathrm{H}_{2} \mathrm{O}\right)_{6}\right]^{2+}$ octahedra through a system of hydrogen bonds. There is a known series of minerals with ktenasite type structure: serpierite, devilline, niedermayrite, edwardsite, kobyashevite, campigliaite and others. For the first time ktenasite was synthesized by Xue et al. (2004) using simple method of mixing $\mathrm{ZnO}$ powder with $\mathrm{CuSO}_{4}$ solution at room temperature and characterized by different analytical methods in order to evaluate its intercalation processes. Some data on the thermal behavior of the ktenasite can be find in that paper.

There is no detailed analysis in the literature toward the processes, the solid products and volatiles during the ktenasite thermal decomposition. It is known that the thermal decomposition of copper hydroxide sulfates and zinc hydroxide sulfates leads to the formation of $\mathrm{CuO}$ (Koga et al., 2008) and $\mathrm{ZnO}$ (Moezzi et al., 2013; Liang et al., 2015), respectively as final products with various desired properties and applications. In contrast to the detailed characteristics of the thermal decomposition of various $\mathrm{Zn}$-hydroxy-salt minerals with the final product $\mathrm{ZnO}$ (Stanimirova et al., 2016), the ther- mal behavior of $\mathrm{Cu}$-hydroxy-salt minerals has been poorly studied.

The aim of this paper is to report preliminary data concerning the thermal behavior of the ktenasite based on analysis of decomposition processes and obtained products using combined thermal and XRD methods.

\section{Experimental}

The ktenasite was prepared by a chemical reaction between $1 \mathrm{~g}$ of $\mathrm{ZnO}$ powder and $10 \mathrm{ml} 1 \mathrm{M}$ solution of $\mathrm{CuSO}_{4}$ with periodical steering at room temperature for 7 days. The obtained suspension was filtered, washed with distilled water, and dried at room temperature.

The DSC-TG analyses were carried out on apparatus SETSYS2400, Evolution, SETARAM at the following conditions: temperature range from 20 to $1000{ }^{\circ} \mathrm{C}$, in a static air atmosphere, with a heating rate of $10^{\circ} \mathrm{C} \mathrm{min}^{-1}$, and $10-15 \mathrm{mg}$ sample mass. Simultaneous analysis of the evolved gases was performed via mass spectrometry using an OmniStar mass spectrometer connected to the TG apparatus.

The phase composition of the initial sample and products obtained during thermal decomposition was studied by powder X-ray diffractometer D2 Phaser Brucker AXS with $\mathrm{Cu}-\mathrm{K} \alpha$ radiation in steps of $0.02^{\circ} \mathrm{s}^{-1}$.

\section{Results and discussion}

Data of the DSC-TG (DTG)-MS and the XRD patterns of the initial ktenasite and the products of its thermal decomposition are shown on Fig. 1A-B. The XRD data of the synthesized ktenasite (Fig. 1 B) bottom) correspond to the reference in the ICSD 
database (PDF No 83-2247). The reflections of the synthesized ktenasite are comparable to those of synthetic ktenasite reported in the literature (Xue et al., 2004; Stanimirova et al., 2019). On the XRD pattern of the initial sample, a small amount (about 5 mass \% estimated by program PowderCell) of brochantite (PDF No 84-0454) is also registered. Probably, its appearance is due to intensive washing of the ktenasite precipitate following synthesis. For such transformation of ktenasite into brochantite through leaching of the ion pair (the interlayer $\mathrm{M}^{2+}$ and the hydroxide layer bonded $\mathrm{SO}_{4}{ }^{2-}$ ) under water treatment was recently reported (Stanimirova et al., 2019).

Dehydration: In the low-temperature interval $\left(20-380{ }^{\circ} \mathrm{C}\right)$, four endo-effects on the DSC-curve are registered (Fig. 1 A, 1-4), which suggests a complicated process of dehydration. The MS analysis shows leaving only of water molecules in this region. The water molecules of the ktenasite structure are not in free stage in the interlayer and octahedral coordinate the $\mathrm{Zn}$ cations. Some of the water mol- ecules play role of charge balancing bridge between $\mathrm{Zn}^{2+}$ and $\mathrm{O}$ atoms from $\mathrm{SO}_{4}{ }^{2-}$. Apparently, the interaction of the water molecules with the $\mathrm{Zn}$ cation and the oxygen atom of the sulfate group causes a different energy of stage-by-stage dehydration. Two $\mathrm{H}_{2} \mathrm{O}$ molecules leave the ktenasite structure according to the data from the TG analysis within the endo-effect 1. At that time, the XRD data show an interlayer shrinking of $1.33 \AA\left(\mathrm{d}_{002}\right.$ from 11.78 to $10.45 \AA$ ), Fig. 1B), which is evidence for the presence of partially dehydrated form of ktenasite. The analysis of the XRD data shows that this partially dehydrated phase is isostructural with the mineral christelite, also a layered $\mathrm{Cu}-\mathrm{Zn}$ hydroxy sulfate composed by a ktenasite-type hydroxide layer. In christelite structure the interlayer $\mathrm{Zn}$ cation is also octahedral coordinated, but octahedron consists of $4 \mathrm{H}_{2} \mathrm{O}$ and two oxygen atoms from two adjacent sulfate groups.

The next dehydration of the ktenasite (in the framework of endo-effects 2 and 3 ) leads to the formation of antlerite (PDF $\mathrm{N}^{\circ}$ 76-1621), an anhyd-
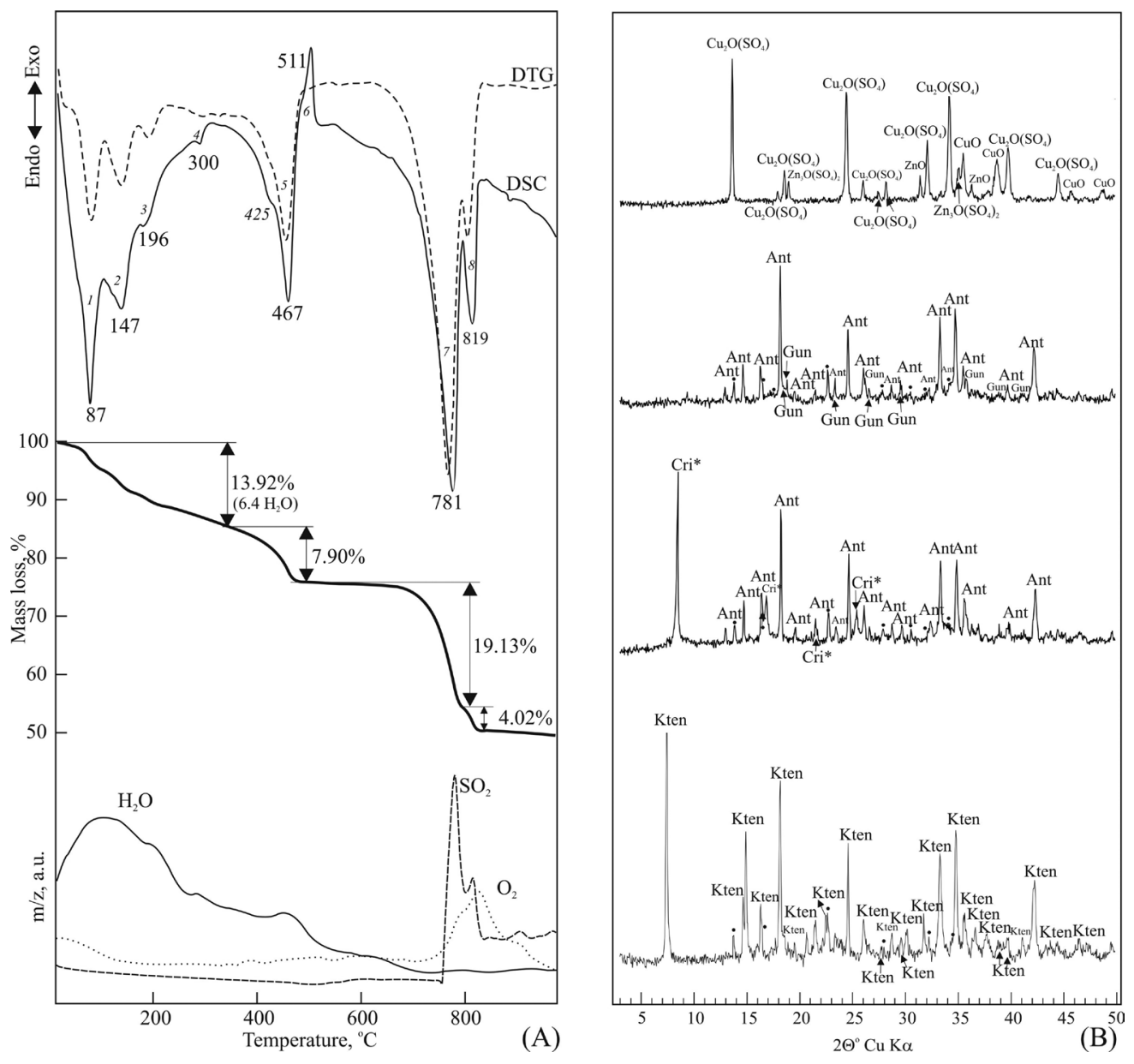

Fig. 1. DSC-TG-MS data: $A$, for Ktenasite and powder XRD patterns; $B$, of initial and thermally treated samples. Initial and product samples of thermal decomposition were marked as follows: Kten - ktenasite; Cri* - isostructural with christelite partial dehydrated ktenasite; Ant - antlerite; Gun - gunningite. The impurity brochantite is marked with $\bullet$ 
rous copper hydroxy sulfate mineral and gunningite (PDF No 74-1331), a zinc sulfate monohydrate mineral, Fig. 1B). Apparently, the departure of three more water molecules from the environment of the interlayer $\mathrm{Zn}$ cation enhances the interaction of $\mathrm{Zn}^{2+}$ cations with the sulfate groups, separating them from the hydroxide layer and forming gunningite. After this process, half of the sulfate anions remain in the hydroxide layer, as the quantitative ratios of $\mathrm{Zn}^{2+}$ and $\mathrm{SO}_{4}{ }^{2-}$ in the ktenasite structure are 1:2. The calculated losses in the range of 2 and 3 endo-effects have a yield of about $3.5 \mathrm{H}_{2} \mathrm{O}$ (Fig. 1A). The higher amount of the water released is a result of the restructuring of the hydrate-free hydroxide layer (type brochantite $\mathrm{Cu}_{4}(\mathrm{OH})_{6} \mathrm{SO}_{4}$ ) into an antlerite layer $\left(\mathrm{Cu}_{3}(\mathrm{OH})_{4} \mathrm{SO}_{4}\right)$, which is associated with the separation of one $\mathrm{OH}$ group. The gunningite losses its water molecule within endo effect 4 in the same manner and the temperature range of $250-350{ }^{\circ} \mathrm{C}$ us in the publications of Straszko et al., (1997) and Posern et al. (2014). As can see from DSC-TG curves both dehydration and partial dehydroxilation finish up to $380^{\circ} \mathrm{C}$. We take in consideration as well the presence of brochantite ( 5 mass $\%$ in the initial sample) and in this way $6.4 \mathrm{H}_{2} \mathrm{O}$ molecules leave the system up to $380{ }^{\circ} \mathrm{C}$. Thus, the scheme of thermal decomposition in the low temperature region (1-4 endo-effect) can be described as follows:

$$
\begin{aligned}
& \mathrm{ZnCu}_{4}(\mathrm{OH})_{6}\left(\mathrm{SO}_{4}\right)_{2} \cdot 6 \mathrm{H}_{2} \mathrm{O} \frac{20 \div 100^{\circ} \mathrm{C}}{-2 \mathrm{H}_{2} \mathrm{O}} \rightarrow \\
& \mathrm{ZnCu}_{4}(\mathrm{OH})_{6}\left(\mathrm{SO}_{4}\right)_{2} \cdot 4 \mathrm{H}_{2} \mathrm{O} \quad \frac{150 \div 250^{\circ} \mathrm{C}}{-\left(3 \mathrm{H}_{2} \mathrm{O}+\mathrm{OH}\right)} \rightarrow \\
& \mathrm{ZnSO}_{4} \cdot \mathrm{H}_{2} \mathrm{O}+1.25 \mathrm{Cu}_{3}(\mathrm{OH})_{4} \mathrm{SO}_{4} \frac{250 \div 350^{\circ} \mathrm{C}}{-\mathrm{H}_{2} \mathrm{O}} \rightarrow \\
& \mathrm{ZnSO}_{4}+1.25 \mathrm{Cu}_{3}(\mathrm{OH})_{4} \mathrm{SO}_{4} .
\end{aligned}
$$

Dehydroxylation: This process is observed within endo-effect 5 on DSC curve in temperature interval $380-550^{\circ} \mathrm{C}$. As can expected only water is registered by MS gas-evolving method. It is known that the dehydrohylation of both brochantite and antlerite take place in this temperature region maximizing at 430 and $470{ }^{\circ} \mathrm{C}$, respectively (Koga et al., 2008). The same tendency is observed in our investigation where the insignificant presence of brochantite explains the appearance of a shoulder to the antlerite dehydrohylation peak. The observed exothermic effect 6 at $511^{\circ} \mathrm{C}$ is ascribed to the crystallization of $\mathrm{Cu}_{2} \mathrm{O}\left(\mathrm{SO}_{4}\right)$ (PDF No 78-0612), and $\mathrm{CuO}$ (Uzunov et al., 1995; Koga et al., 2008). During this period the $\mathrm{ZnSO}_{4}$ obtained after the gunningite dehydration transforms consequently into two allotropes and to the basic salt $\mathrm{Zn}_{3} \mathrm{O}\left(\mathrm{SO}_{4}\right)$ which remains stable up to $800^{\circ} \mathrm{C}$ (Straszko et al., 1997). Our XRD data show the presence of $\mathrm{Zn}_{3} \mathrm{O}\left(\mathrm{SO}_{4}\right)$ ( $\mathrm{PDF} \mathrm{N}^{\circ} 32-1475$ ) as well. During this process $3.5 \mathrm{H}_{2} \mathrm{O}$ molecules leave the system as can estimate from the TG curve.
$\mathrm{SO}_{4}$ degradation: This process proceeds in the temperature interval $700-1000{ }^{\circ} \mathrm{C}$ in the range of endo-effects 7 and 8 on the DSC curve. MS analysis data show the presence of $\mathrm{SO}_{2}$ and $\mathrm{O}_{2}$ as evolving gases. The effect 7 points the decomposition of $\mathrm{Cu}_{2} \mathrm{O}\left(\mathrm{SO}_{4}\right)$ (Koga et al., 2008) followed by the decomposition of $\mathrm{Zn}_{3} \mathrm{O}\left(\mathrm{SO}_{4}\right)_{2}$ (endo-effect 8 ) (Straszko et al., 1997; Stanimirova et al., 2016). Tenorite $(\mathrm{CuO})$ and zincite $(\mathrm{ZnO})$ are obtained as final products of the thermal decomposition.

Finally, we may conclude that the thermal decomposition process of the ktenasite including different processes such as dehydration, dehydroxylation and evolving of $\mathrm{SO}_{2}$ and $\mathrm{O}_{2}$ is rather complicated due to the simultaneous presence of both copper and zinc in the system and this suggests further investigations to clarify the reaction mechanism of the process.

Acknowledgements: This work was supported by the Bulgarian Ministry of Education and Science under the National program "Young scientists and postdoctoral students".

\section{References}

Koga, N., K., A. Mako, T. Kimizu, Y.Tanaka. 2008. Thermal decomposition of synthetic antlerite prepared by microwave-assisted hydrothermal method. - Thermochimica Acta, 467, 11-19.

Kokkoros, P. 1950. Ktenasit, ein Zink-Kuprefersalt aus Lavrion (Griechenland). - Tschemarks Mineral. Petrogr. Mitt., 3, 1, 342-346.

Liang, W., W. Li, H. Chen, H. Liu, L. Zhu. 2015. Exploring electrodeposited flower-like $\mathrm{Zn}_{4}(\mathrm{OH})_{6} \mathrm{SO}_{4} \cdot 4 \mathrm{H}_{2} \mathrm{O}$ nanosheets as a precursor for porous $\mathrm{ZnO}$ nanosheets. - Electrochim. Acta, 156, 171-178.

Mellini, M., S. Merlino. 1978. Ktenasite, another mineral with ${ }_{\infty}^{2}\left[(\mathrm{Cu}, \mathrm{Zn})_{2}(\mathrm{OH})_{3} \mathrm{O}\right]^{-}$octahedral sheets. -Zeitshrift für Kristallographie, 147, 129-140.

Moezzi, A., M. B. Cortie, A. M. McDonagh. 2013. Zinc hydroxide sulfate and its transformation to crystalline zinc oxide. - Dalton Trans., 42, 14432-14437.

Stanimirova, Ts., N. Petrova, G. Kirov. 2016. Thermal decomposition of zinc hydroxy-sulfate-hydrate minerals. $-J$. Thermal Anal. Calorimetry, 1, 85-96.

Stanimirova, Ts., Kr. Ivanova. 2019. Transformation of ktenasite-type minerals to langite, posnjakite, and brochantite under water treatment. - C. R. Acad. Bulg. Sci., 72, 6, 768-777.

Straszko, J., M. Olszak-Humienik, J. Mozejko. 1997. Kinetics of thermal decomposition of $\mathrm{ZnSO}_{4} \cdot 7 \mathrm{H}_{2} 0$. - Thermochimica Acta, 292, 145-150.

Posern, K., K. Linnow, Ch. Kaps, M. Steiger. 2014. Investigations of $\mathrm{ZnSO}_{4}$ hydrates for solar heat storage applications. - In: EuroSun 2014, ISES Conference Proceedings, 1401-1406

Uzunov, I., D. Klissurski, L. Teocharov. 1995. Thermal decomposition of basic copper sulphate monohydrate. - Journal of Thermal Analysis, 44, 3, 685-696.

Xue, M., R. Chitrakar, K. Sakane, K. Ooi, Sh. Kobayashi, M. Ohnishi, A. Doic. 2004. Synthesis of ktenasite, a double hydroxide of zinc and copper, and its intercalation reaction. - Journal of Solid State Chemistry, 177, 1624-1630. 